\title{
Prioritizing Drivers and Barriers for Applying Green Manufacturing with a System Model Approach: A Case Study
}

\author{
Sumaiya Shahria ${ }^{1}$, Mst. Nazma Sultana ${ }^{2}$, Md. Tariquzzaman ${ }^{2}$, Md. Habibur Rahman ${ }^{2, *}$ \\ ${ }^{1}$ Department of Textile Engineering, Khwaja Yunus Ali University, Sirajganj, Bangladesh \\ ${ }^{2}$ Department of Industrial Engineering and Management, Khulna University of Engineering \& Technology (KUET), Khulna, Bangladesh
}

Email address:

habibur091@gmail.com (Md. H. Rahman)

${ }^{*}$ Corresponding author

\section{To cite this article:}

Sumaiya Shahria, Mst. Nazma Sultana, Md. Tariquzzaman, Md. HabiburRahman. Prioritizing Drivers and Barriers for Applying Green Manufacturing with a System Model Approach: A Case Study. International Journal of Economics, Finance and Management Sciences. Vol. 7, No. 1, 2019, pp. 21-28. doi: 10.11648/j.ijefm.20190701.15

Received: January 7, 2019; Accepted: February 19, 2019; Published: March 12, 2019

\begin{abstract}
Green manufacturing is the process of producing product by minimizing natural resource use, reducing environmental pollution or wastes. Garment industry in Bangladesh plays a vital role in the country's economy. But most of these industries are indifferent to environmental regulation. A huge amount of river water is being polluted daily by the dyeing sections. So it is necessary to treat the water to a standard level before discharge. The purpose of this research is to establish an approach for the modification of dyeing section of textile industries. Before going to the approach a survey with some questionnaire was performed to identify drivers and barriers regarding green manufacturing implementation. Then these drivers and barriers were ranked with fuzzy TOPSIS tool. A system model was followed for making an approach of green manufacturing. ETP (Effluent Treatment plant) plant is suggested along with an existing dyeing process for treating waste water.
\end{abstract}

Keywords: Green Manufacturing, Drivers, Barriers, System Model, Effluent Treatment Plant, Fuzzy

\section{Introduction}

Bangladesh is a country which is the twentieth largest garment-manufacturing nation in the world. The country's foreign exchange earnings from garment sector now accounts for about $77 \%$, and $50 \%$ of its industrial work force. A report by the World Bank (2010) showed the environmental impacts of readymade garment on the basis of four categories - Yarn production, Fabric production, Dyeing and finishing and Garment production. The environmental pollution was measured along water contamination, energy usage, and chemicals discharged. It clearly indicated that the environment is polluted mostly by the dyeing and finishing section. There is nation's standard for concentration of effluents for the textile sector. But it is merely maintained. Violation of this standard is mostly performed by the dyeing section of textile industries. The research and industrial communities are taking interest in green manufacturing more and more, since a clear description of what is meant by this term is becoming more essential GM (Green Manufacturing) implementation faces many challenges. For the purpose of making these changes possible, motivation from the government as well as from the industries should be provided with some awareness of cumbering factors. The prioritization plays a vital role for the emerging and developing economies because of the limited financial and other resources. The prioritization of GM drivers and barriers are expected to help the government and industry to focus vital drivers and to overcome the barriers to facilitate the GM implementation. The implementation of GM is initiated by proposing a system model that will incorporate planning activities and qualitative approach for GM. Textile industries are facing increasing number of challenges from environmental issues and environmental legislation which includes increased cost of water, implementation of more stringent, increased cost of effluent treatment and disposal, regulations, toxicity and 
salinity, eco labels and new legislation especially in terms of color, and the introduction of ISO 14001 [1-3]. At present sustainability-driven management are being adopted by most of the businesses however, adoption level varies among companies [4]. Drivers and barriers for green manufacturing have been identified by different studies in the past [5-8]. From the combined assistance of industrial managers, existing literature, and experts opinion in the relevant field twelve drivers were identified for green manufacturing [9]. Strategies concerning environmental conscious manufacturing factors [5-6], efficient manufacturing with energy and resources [10], a preliminary findings of drivers and barriers for small and medium size enterprises [3, 11], managing the environment [12], and environmentally sound technology adoption [13]. Fuzzy TOPSIS multi-criteria decision making (MCDM) technique is used to prioritize the drivers and barriers because it is an improved practice to deal with two most important kinds of uncertainties, i.e. vagueness and ambiguity that exist in the real life. Also, fuzzy TOPSIS methodology offers ease of computation with better understanding [14]. In the TOPSIS approach an alternative that is nearest to the Fuzzy Positive Ideal Solution (FPIS) and farthest from the Fuzzy Negative Ideal Solution (FNIS) is chosen as optimal [15-16]. The literature of green manufacturing is missing a clear roadmap for manufacturing enterprises that can assess the existing level of their greenness and offer a structured transformation plan towards becoming greener. A system model is approached for dyeing section of industries to fill this requisite gap [17]. In recent years, there is a tendency to use biological treatment systems to treat dye-bearing wastewaters. Biological treatment technologies have been considered more efficient in treating waste water [12, 18-20].

Above review reveals that some preliminary findings of drivers and barriers for green manufacturing were performed by some researchers but they were all based on overall green manufacturing implementation. Also no studies examined Bangladeshi manufacturing origin. It is difficult for a company to adopt green manufacturing practices all along. They need a sample model along with drivers and barriers to initiate for this approach. This study compensates for these difficulties. The highlights of this research are given sequentially- Drivers and barriers are identified concerning dyeing section of textile industries of Bangladesh through expert's recommendations and expert reviews, collected drivers and barriers are prioritized with fuzzy TOPSIS tool to take the advantages of motivational factors and to overcome obstacles, a general system model for green manufacturing (concerning an industrial case) is proposed, finally the obtained results are further analyzed and a modification of existing dyeing process is proposed with a modern technology.

This article is organized into five sections for the completion its objectives and the organization is industrial case in section 2, research methodology in section 3, results and discussion in section 4, conclusion and recommendations in section 5 .

\section{Industrial Case}

In textile processing there are three major areas of waterPre-cleaning and rinsing of fabric or yarn prior to dyeing or printing. During printing or dyeing operation, soaping and processing activities after-treatment. Rinsing along with others such as boiler, ion exchange, cooling water, cleaning, and steam drying etc. [21].

Several pollutants from wastewater or effluent originated from yarn dyeing, sizing, bleaching, fancy dyeing, mercerizing screen printing, and finishing are actually biproduct of the products produced by the textile and dyeing industries [21]. Now that effluent removal (and chemical) costs are increasing, many companies are, almost literally, throwing money down the drain. It is not necessarily true that to save money you first need to spend money. The first step towards saving money by reducing water use and effluent strength is to appreciate and review water and chemical use throughout the site. A list of potential actions can be drawn giving priority to those that are easy to implement and likely to be the most cost-effective. Implementing those actions will achieve savings. A process flow chart for dyeing was collected from a knit processing industry which is not currently adopting green manufacturing practices. It discharges water after each process into the river without treating it. So after searching for literature pertaining to water treatment a methodology has been proposed with preliminary findings of drivers and barriers followed by an approach of system model for green manufacturing.

\section{Methodology}

\subsection{Drivers and Barrier Identification}

To identify drivers and barriers for green manufacturing a list of questionnaires were prepared and a survey was performed through e-mail in some textile industries in Bangladesh. Forty three e- mails were sent to executive and managerial level but twenty six of them were replied. Various research papers for GM were also analyzed. Ten drivers (D) and eleven barriers (B) were selected for our research based on the opinions of experts from different departments

\subsection{Ranking of Drivers and Barriers}

Fuzzy TOPSIS (Technique for Order Preference by Similarity to Ideal Solution) developed by Chen, is a sensible method and helps human thinking under real environment [22]. Four decision makers (DM) were selected among experts and fuzzy theory was applied to prioritize drivers and barriers. The steps of fuzzy TOPSIS algorithm that was followed during our research is expressed as follows [23].

Step 1: A proper scale must be chosen to represent the data. Respondents must be asked to select the best alternative among the linguistics terms for a given question. Fuzzy numbers for the selected linguistics terms are presented in table below- 
Table 1. Linguistic terms and corresponding fuzzy number.

\begin{tabular}{ll}
\hline Linguistic term & Fuzzy number \\
\hline Low(L) & $(0.0,0.1,0.3)$ \\
Fairly low(FL) & $(0.1,0.3,0.5)$ \\
Medium(M) & $(0.3,0.5,0.7)$ \\
Fairly high(FH) & $(0.5,0.7,0.9)$ \\
High(H) & $(0.7,0.9,1.0)$ \\
\hline
\end{tabular}

To transform the linguistic terms into fuzzy numbers, fuzzy set theory requires an application of a conversion scale. Table 1 shows linguistic terms and their corresponding fuzzy number. In this paper, a rating scale of 0 to 1 will be applied to rate the criteria. Considering the fuzziness and distance among the criteria the linguistic variables were chosen for the values of triangular fuzzy number.
Step 2: Evaluating the following fuzzy decision matrix

$$
\mathrm{D}=\left[\begin{array}{cccccc}
x_{11} & x_{12} & \cdots & x_{1 j} & \cdots & x_{1 n} \\
x_{21} & x_{22} & \cdots & x_{2 j} & \cdots & x_{2 n} \\
\cdots & \cdots & \cdots & \cdots & \cdots & \cdots \\
x_{i 1} & x_{i 2} & \cdots & x_{i j} & \cdots & x_{i n} \\
\cdots & \cdots & \cdots & \cdots & \cdots & \cdots \\
x_{m 1} & x_{m 2} & \cdots & x_{m j} & \cdots & x_{m n}
\end{array}\right]
$$

Where, a fuzzy number corresponding to the linguistic term assigned by the decision maker (DM) to the $\mathrm{j}^{\text {th }}$ factor. $\mathrm{i}=1,2 \ldots \mathrm{m}$ are the number of DMs and $\mathrm{j}=1,2 \ldots \mathrm{n}$ are the number of Critical Success Factors (CSFs).

Table 2. Decision matrix using linguistic variable.

\begin{tabular}{|c|c|c|c|c|}
\hline \multirow{2}{*}{ Barriers } & \multicolumn{4}{|c|}{ Decision Makers } \\
\hline & DM1 & DM2 & DM3 & DM4 \\
\hline Result could be unexpected (B1) & $\mathrm{FH}$ & M & $\mathrm{FL}$ & M \\
\hline GM is considered as non-value added (B2) & FH & M & M & FH \\
\hline Work stations aren't designed Ergonomically(B3) & M & FH & $\mathrm{H}$ & M \\
\hline Indifferent to waste management system (B4) & $\mathrm{FH}$ & FH & FH & M \\
\hline People's dependency on conventional method (B5) & FH & FH & M & $\mathrm{H}$ \\
\hline No proper execution of laws (B6) & $\mathrm{L}$ & M & $\mathrm{L}$ & FL \\
\hline No inspiration or motivation(B8) & $\mathrm{H}$ & $\mathrm{H}$ & $\mathrm{FH}$ & $\mathrm{FH}$ \\
\hline No strong demand from owner (B9) & FL & FL & $\mathrm{L}$ & FL \\
\hline High expenditure of innovation (B10) & M & M & FL & $\mathrm{L}$ \\
\hline Guaranty of compensation (B11) & M & $\mathrm{H}$ & M & M \\
\hline
\end{tabular}

Table 2 shows a decision matrix using linguistic variable for the various barriers criteria. Based on experience four decision makers were chosen to give their weights for the eleven criteria. Their importance was given in terms of five linguistic terms as Low (L), Fairly Low (FL), Medium (M), Fairly High $(\mathrm{FH})$ and High $(\mathrm{H})$ concerning emphasis of each criterion.

Step 3: Neutralizing the weight of decision matrix and generating fuzzy un-weighted matrix (R).

If fuzzy ratings of all decision makers are described as triangular fuzzy numbers

$$
R_{k}=\left(a_{k}, b_{k}, c_{k}\right), k=1,2, \ldots \ldots \ldots \ldots, K
$$

Where

$$
\begin{aligned}
& a=\min _{k}\left\{a_{k}\right\} \\
& b=1 / K \sum b_{k} \\
& c=\max \left\{c_{k}\right\}
\end{aligned}
$$

Then the aggregate fuzzy rating is given by Eq. (2)

$$
R=\left[r_{i j}\right]_{m * n}
$$

$$
r_{i j}=\left(\frac{a_{i j}}{c_{j}^{*}}, \frac{b_{i j}}{c_{j}^{*}}, \frac{c_{i j}}{c_{j}^{*}}\right),
$$

Where

$$
c_{j}^{*}=\max _{i} c_{i j}
$$

Step 4: Calculating the weighted normalized decision matrix.

$$
\begin{gathered}
V=\left[v_{i j}\right]_{m * n} \\
i=1,2, \ldots \ldots \ldots, \text { mand } j=1,2, \ldots \ldots \ldots, n
\end{gathered}
$$

The weighted normalized value $v_{i j}$ is calculated as Where

$$
\left[v_{i j}\right]=r_{i j} * w_{j}
$$

Where $w_{j}$ is the weight given to each decision-maker.

$$
w_{i}=(1,1,1,1,1) \forall j \in n
$$

Because, all the DMs are considered to have same weight for this study.

And 
Table 3. Aggregate fuzzy weights for barriers.

\begin{tabular}{|c|c|c|c|c|c|c|c|c|c|c|c|}
\hline \multirow{2}{*}{ Decision Makers } & \multicolumn{11}{|c|}{ Barriers } \\
\hline & B1 & B2 & B3 & B4 & B5 & B6 & B7 & B8 & B9 & B10 & B11 \\
\hline DM1 & $.5, .7, .9$ & $.5, .7, .9$ & $.3,5, .7$ & $.5, .7, .9$ & $.5,7, .9$ & $0, .1, .3$ & $.3, .5,77$ & $.7, .9,1$ & $.1, .3, .5$ & $.3, .5, .7$ & $.3, .5, .7$ \\
\hline DM2 & $.3, .5, .7$ & $.3, .5, .7$ & $.5, .7, .9$ & $.5, .7, .9$ & $.5,7, .9$ & $.3,5, .7$ & $0, .1, .3$ & $.7, .9,1$ & $.1, .3, .5$ & $.3, .5, .7$ & $.7, .9,1$ \\
\hline DM3 & $.1, .3, .5$ & $.3, .5, .7$ & $.7,9,1$ & $.5,7, .9$ & $.3,5,77$ & $0, .1, .3$ & $.3,5, .7$ & $.5,7, .9$ & $0, .1, .3$ & $.1, .3, .5$ & $.3, .5, .7$ \\
\hline DM4 & $.3, .5, .7$ & $.5, .7,99$ & $.3,5, .7$ & $.3, .5,77$ & $.7,9,1$ & $.1,3, .5$ & $.5, .7, .9$ & $.5, .7, .9$ & $.1, .3, .5$ & $0, .1,3$ & $.3, .5, .7$ \\
\hline
\end{tabular}

After having all the criteria with their importance in linguistic term it becomes necessary to interpret this linguistic term with fuzzy number for further calculation. For each linguistic term a certain fuzzy number is maintained (as shown in table 1) and it is shown in table 3. Aggregate fuzzy weights for criteria are put in the row whereas decision makers are put on column wise.

Step 5: Determining the positive ideal and negative-ideal solution for the CSFs proposed by Chen [22]

$$
\begin{aligned}
A^{*} & =\left(v_{1}^{*}, v_{2}^{*}, \ldots, v_{n}^{*}\right) \\
A^{-} & =\left(v_{1}^{-}, v_{2}^{-}, \ldots, v_{n}^{-}\right)
\end{aligned}
$$

Since the positive and negative ideas introduced by Chen [22] are used for the research. The following terms are used for ideal and negative ideal solution

$$
\begin{gathered}
v_{j}^{*}=(1,1,1) \\
v_{j}^{-}=(0,0,0)
\end{gathered}
$$

Step 6: Calculate the sum of distances from positive and negative ideal solution for each factor.

$$
D_{j}^{*}=\frac{\sum_{i=1}^{m} d\left(v_{i j}-v_{i}^{*}\right)}{m} \text { wherej }=1,2, \ldots \ldots n
$$

$\mathrm{D}\left(v_{i j}-v_{i}^{*}\right)$ is the distance between two fuzzy numbers which can be calculated using the vector algebra. For example distance between two numbers A1 $\left(a_{1}, b_{1}, c_{1}\right)$ and

\begin{tabular}{|c|c|c|c|c|c|c|c|c|c|c|c|}
\hline Decision Makers & B1 & B2 & B3 & B4 & B5 & B6 & B7 & B8 & B9 & B10 & B11 \\
\hline DM1 & .342 & .342 & .525 & .342 & .342 & .876 & .525 & .183 & .719 & .525 & .525 \\
\hline DM2 & .525 & .525 & .342 & .342 & .342 & .525 & .876 & .183 & .719 & .525 & .183 \\
\hline DM3 & .719 & .525 & .183 & .342 & .525 & .876 & .525 & .342 & .876 & .719 & .525 \\
\hline Average & .528 & .434 & .394 & .388 & .348 & .749 & .567 & .2623 & .758 & .661 & .440 \\
\hline
\end{tabular}
$\mathrm{A} 2\left(a_{1}, b_{1}, c_{1}\right)$ can be calculated as

$$
d(A 1-A 2)=\sqrt{\frac{1}{3}\left[\left(a_{2}-a_{1}\right)^{2}+\left(b_{2}-b_{1}\right)^{2}+\left(c_{2}-c\right)^{2}\right]}
$$

Table 4. Distance $D_{j}^{*}$ for barriers.

Table 4 shows separation from positive ideal solution for each barrier criterion. The positive ideal solution is composed of all best criteria values attainable. According to

\begin{tabular}{|c|c|c|c|c|c|c|c|c|c|c|c|}
\hline Decision Makers & B1 & B2 & B3 & B4 & B5 & B6 & B7 & B8 & B9 & B10 & B11 \\
\hline DM1 & .719 & .719 & .526 & .719 & .719 & .183 & .526 & .879 & .342 & .526 & .526 \\
\hline DM2 & .526 & .526 & .719 & .719 & .719 & .526 & .183 & .879 & .342 & .526 & .879 \\
\hline DM3 & .342 & .526 & .879 & .719 & .526 & .183 & .526 & .719 & .183 & .342 & .526 \\
\hline DM4 & .526 & .719 & .526 & .526 & .879 & .342 & .719 & .719 & .342 & .183 & .526 \\
\hline Average & .528 & .622 & .662 & .6708 & .710 & .309 & .489 & .796 & .302 & .394 & .614 \\
\hline
\end{tabular}
the concept of TOPSIS it is defined as positive ideal solution

(FPIS).

$$
D_{j}^{-}=\frac{\sum_{i=1}^{m} d\left(v_{i j}-v_{i}^{-}\right)}{m} \mathrm{j}=1,2 \ldots \mathrm{n}
$$

Table 5. Distance $D_{j}^{-}$for barriers.

Table 5 shows separation from negative ideal solution for each barrier criterion. The negative ideal solution is composed of all worst criteria values attainable. According to the concept of TOPSIS it is defined as positive ideal solution (FNIS).

Step 7: Calculate the relative closeness to the ideal solution. The relative closeness with respect to $A^{*}$ is defined as

$$
\mathrm{CCj}=\frac{D_{j}^{-}}{D_{j}^{*}+D_{j}^{-}} \mathrm{j}=1,2 \ldots, \mathrm{n}
$$

Step 8: Prioritize the preference order based on the order of the values of $C C_{j}$.

Table 6. Closeness coefficients $\left(C C_{j}\right)$ of the barriers.

\begin{tabular}{lllll}
\hline SI. No & Barriers & $\boldsymbol{D}^{*}$ & $\boldsymbol{D}^{-}$ & CC $_{\mathbf{j}}$ \\
\hline 1 & Result could be unexpected (B1) & .528 & .528 \\
2 & GM is considered as non-value added (B2) & .434 & .500 \\
3 & Work stations are not designed Ergonomically(B3) & .622 & .590 \\
\hline
\end{tabular}




\begin{tabular}{|c|c|c|c|c|c|}
\hline SI. No & Barriers & $D^{*}$ & $D^{-}$ & $\mathbf{C C}_{\mathbf{j}}$ & Priority \\
\hline 4 & Indifferent to waste management system (B4) & .388 & .6708 & .634 & 3 \\
\hline 5 & People's dependency on conventional method(B5) & .348 & .710 & .716 & 2 \\
\hline 6 & No proper execution of laws (B6) & .749 & .309 & .292 & 10 \\
\hline 7 & Compliance with ethical and environmental standard is not maintained (B7) & .567 & .489 & .463 & 8 \\
\hline 8 & No inspiration or motivation(B8) & .2623 & .796 & .752 & 1 \\
\hline 9 & No strong demand from owner (B9) & .758 & .302 & .284 & 11 \\
\hline 10 & High expenditure of innovation(B10) & .661 & .394 & .373 & 9 \\
\hline
\end{tabular}

Table 6 shows closeness coefficient of the barriers. After putting the values to the equation no 12 closeness coefficient for each criterion was determined. Criterion having the highest value of closeness coefficient has the first priority and vice versa. The highest value gained was 0.752 for the criterion 'No inspiration or motivation' so was given the first priority. Same case is applied for other the criteria.

With the same algorithm drivers for green manufacturing are also prioritized-

Table 7. Decision matrix using linguistic variable for drivers

\begin{tabular}{|c|c|c|c|c|}
\hline \multirow{2}{*}{ Drivers } & \multicolumn{4}{|c|}{ Decision Makers } \\
\hline & DM1 & DM2 & DM3 & DM4 \\
\hline Financial incentives for GM (D1) & $\mathrm{H}$ & $\mathrm{FH}$ & $\mathrm{FH}$ & $\mathrm{M}$ \\
\hline Organizational Commitment for GM (D2) & FL & M & FH & $\mathrm{FH}$ \\
\hline Owner values or employee aspirations towards GM(D3) & FH & FL & M & $\mathrm{H}$ \\
\hline Availability of Comprehensive training and education in GM (D4) & M & M & FH & FL \\
\hline New market opportunities towards GM (D5) & FL & FL & FH & $\mathrm{H}$ \\
\hline Competitors pressures towards GM (D6) & FL & $\mathrm{H}$ & FH & FL \\
\hline Customer's demand of Green products/process (D8) & FH & FH & FH & FL \\
\hline Organizational belief of cost reductions through GM (D9) & FL & FH & FL & $\mathrm{H}$ \\
\hline Improved company image through GMP (D10) & FH & M & FH & FL \\
\hline
\end{tabular}

Table 8. Aggregate fuzzy weights for drivers.

\begin{tabular}{|c|c|c|c|c|c|c|c|c|c|c|}
\hline Decision Makers & D1 & D2 & D3 & D4 & D5 & D6 & D7 & D8 & D9 & D10 \\
\hline DM1 & $.7, .9,1$ & $.1,3, .5$ & $.5,7, .9$ & $.3, .5,7$ & $.1,3, .5$ & $.1,3, .5$ & $.3,5, .7$ & $.5, .7,9$ & $.1,3, .5$ & $.5,7, .9$ \\
\hline DM2 & $.5, .7, .9$ & $.3, .5, .7$ & $.1,3, .5$ & $.3,5, .7$ & $.1,3, .5$ & $.7,9,1$ & $0, .1, .3$ & $.5,7, .9$ & $.5,7, .9$ & $.3, .5, .7$ \\
\hline DM3 & $.5, .7, .9$ & $.5, .7, .9$ & $.3, .5, .7$ & $.5, .7, .9$ & $.5, .7, .9$ & $.5,7, .9$ & $.3, .5, .7$ & $.5, .7, .9$ & $.1,3, .5$ & $.5, .7,9$ \\
\hline DM4 & $.3,5, .7$ & $.5,7, .9$ & $.7, .9,1$ & $.1,3, .5$ & $.7,9,1$ & $.1,3, .5$ & $.5, .7,9$ & $.1,3, .5$ & $.7, .9,1$ & $.1,3, .5$ \\
\hline
\end{tabular}

Table 9. Distance $D_{j}^{*}$ for drivers.

\begin{tabular}{|c|c|c|c|c|c|c|c|c|c|c|}
\hline Decision Makers & D1 & D2 & D3 & D4 & D5 & D6 & D7 & D8 & D9 & D10 \\
\hline DM1 & .183 & .719 & .342 & .525 & .719 & .719 & .525 & .342 & .719 & .342 \\
\hline DM2 & .342 & .525 & .719 & .525 & .719 & .183 & .876 & .342 & .342 & .525 \\
\hline DM3 & .342 & .342 & .525 & .342 & .342 & .342 & .525 & .342 & .719 & .342 \\
\hline Average & .348 & .482 & .4425 & .52775 & .49075 & .49075 & .567 & .43625 & .491 & .482 \\
\hline
\end{tabular}

Table 10. Distance $D_{j}^{-}$for Drivers.

\begin{tabular}{|c|c|c|c|c|c|c|c|c|c|c|}
\hline Decision Makers & D1 & D2 & D3 & D4 & D5 & D6 & D7 & D8 & D9 & D10 \\
\hline DM1 & .876 & .342 & .719 & .526 & .342 & .342 & .526 & .719 & .342 & .719 \\
\hline DM2 & .719 & .526 & .342 & .526 & .342 & .876 & .183 & .719 & .719 & .526 \\
\hline DM3 & .719 & .719 & .526 & .719 & .719 & .719 & .526 & .719 & .342 & .719 \\
\hline DM4 & .526 & .719 & .876 & .342 & .876 & .342 & .719 & .342 & .876 & .342 \\
\hline Average & .71 & .5765 & .61575 & .52825 & .56975 & .56975 & .4885 & .62475 & .56975 & .5765 \\
\hline
\end{tabular}

Table 11. Closeness coefficients $\left(C C_{j}\right)$ of the drivers.

\begin{tabular}{llllll}
\hline S. No & Drivers & $\boldsymbol{D}_{\boldsymbol{i}}^{*}$ & $\boldsymbol{D}_{\boldsymbol{i}}^{-}$ & $\mathbf{C C}_{\mathbf{j}}$ & Priority \\
\hline 1 & Financial incentives for GM (D1) & .348 & .71 & .671 & 1 \\
2 & Organizational Commitment for GM (D2) & .482 & .5765 & .545 & 4 \\
3 & Owner values or employee aspirations towards GM(D3) & .4425 & .61575 & .582 & \\
4 & Availability of Comprehensive training and education in GM (D4) & .5277 & .52825 & .5 & 9 \\
5 & New market opportunities towards GM (D5) & .49075 & .56975 & .537 & 8 \\
6 & Competitors pressures towards GM (D6) & .49075 & .56975 & .537 & 7 \\
7 & Public awareness to Green initiatives (D7) & .567 & .4885 & .463 & 10 \\
8 & Customer's demand of Green products/process (D8) & .43625 & .62475 & .589 & 2 \\
\hline
\end{tabular}




\begin{tabular}{lllll}
\hline S. No & Drivers & $\boldsymbol{D}_{\boldsymbol{i}}^{*}$ & $\boldsymbol{D}_{\boldsymbol{j}}^{-}$ & $\mathbf{C C}_{\mathbf{j}}$ \\
\hline 9 & Organization's belief of cost reductions through GM (D9) & .491 & .56975 & .537 \\
10 & Improved company image through GM (D10) & .482 & 6 & .5765 \\
\hline
\end{tabular}

\subsection{Establishing an Approach for GM}

A general system model [17] for green manufacturing in the perspective of dyeing section of Bangladeshi textile industries is proposed in figure 1.

In identifying color, output colors can be Black (low), Brown (Medium), Grey (High), and transparent based on green level. Water samples from dyeing sections of different textile industries show significant differences from the standard level. Analyzing present green culture; waste level and eco level a quantitative assessment was performed with structured questionnaires. After the assessment of dyeing section of concerning textile industry the color was chosen as 'Black'. In order to prepare brush, green implementation plan is generated in the beam of previous assessment score. This is particularly important to ensure manufacturers that green improvements or implementation will not pessimistically affect their productivity as traditionally assumed. From the previous assessment score, level of energy consumption, creation of wastes and cost impact, the implementation of
ETP (Effluent treatment plant) is suggested. To paint the existing process green, emphasize is give on how the water should be treated with the ETP and how the layout will be modified and the plant will be implemented. With the successful implementation of these criteria a smooth execution for ETP can be uphold resulting in green manufacturing at dyeing section. Green manufacturing realization should have sustainability as an inherent component in any green planning activity. For keeping the green level, dyeing process with the proper execution of ETP should be practiced. This is not enough. Continuous improvement that is kaizen should also be incorporated. There is no limit for improvement. Purpose of the company should be to look for better level such as online monitoring of effluent level, incorporation of new software, training of the operator etc. Finally green manufacturing policies and guidelines for dyeing section should be established. The two way arrow indicates that the process should be continued until the expected result is obtained.

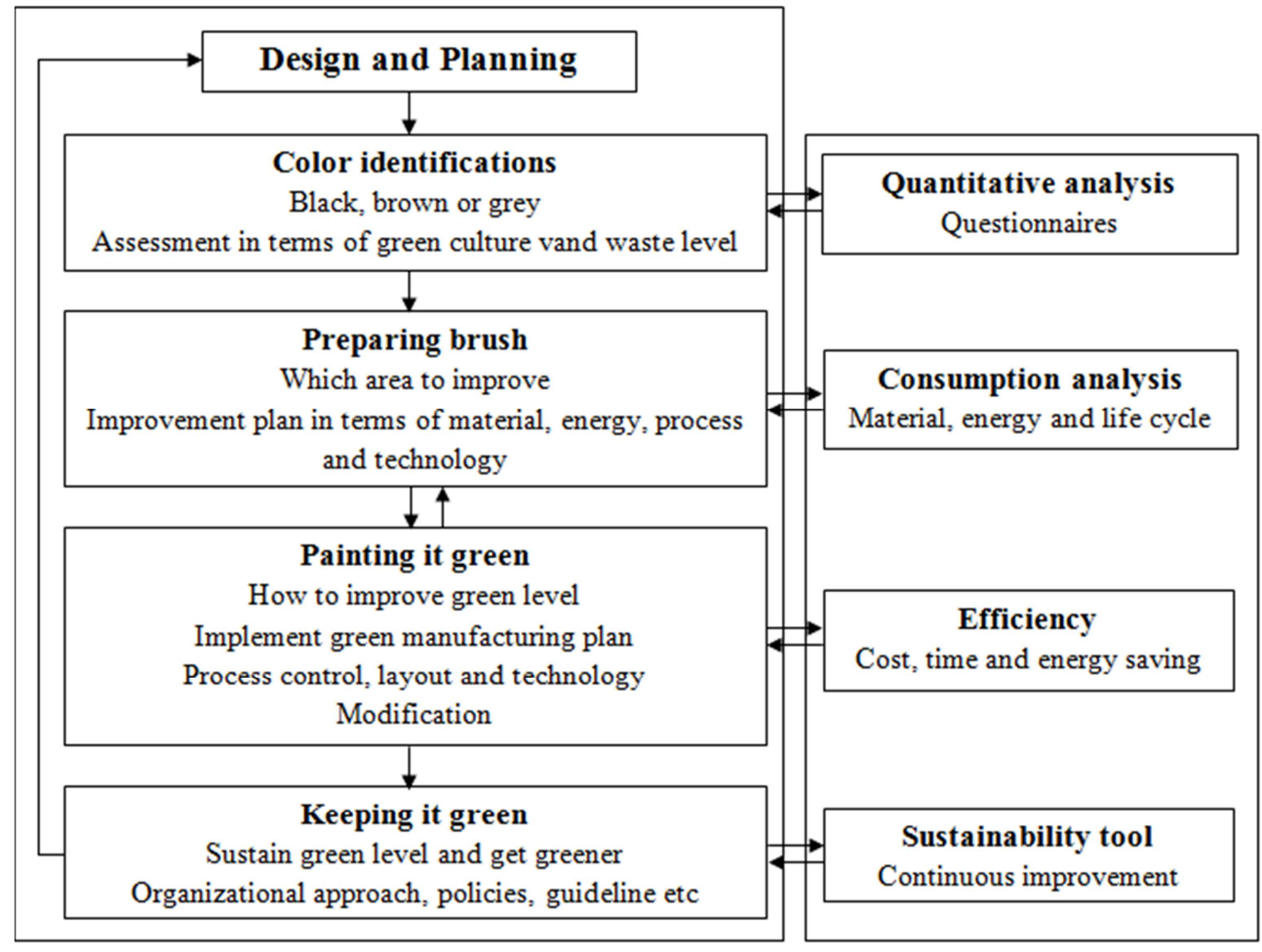

Figure 1. General system model for green manufacturing.

\section{Results and Discussions}

Figure 2 shows the graphical presentation of the importance of GM drivers obtained from fuzzy TOPSIS. The results of MCDM (Multi- Criteria Decision Making) of GM drivers using inputs from Bangladeshi experts reveals that ' financial incentives' is top ranked (1/10) driver which can facilitate the easy implementation of GM in manufacturing industry. For the competitiveness of global market 'customers demand of green product' is ranked second $(2 / 10)$ driver followed by 'owner values or employee aspirations towards GM' (3/10) and so on. Among the least important drivers are - 'public awareness', 'availability of comprehensive training and education' and 'new market 
opportunities'. Public awareness as a driver can influence the implementation of GM after understanding fully its necessity for environment. Companies with poor facility for conducting training and less competitive pressure do not implement newer manufacturing system.

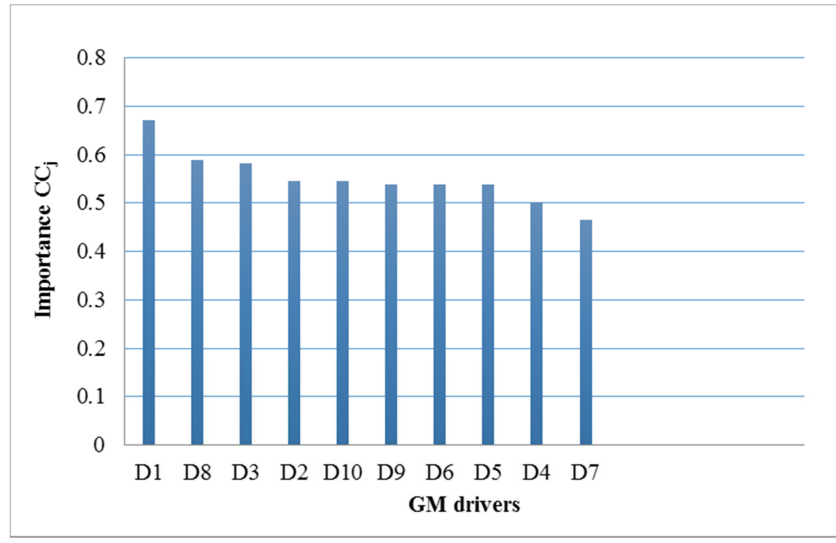

Figure 2. Importance of GM drivers.

Figure 3 shows the graphical presentation of the importance of GM barriers obtained from fuzzy TOPSIS. 'No inspiration or motivation' is the critical barrier among the eleven barriers. Companies negative attitude towards innovations prevent them from adopting new practices. 'People's dependency on conventional method', 'indifferent to waste management system', 'GM is considered as non-value added', 'guaranty of compensation', 'result could be unexpected' etc. are some of prevailing barriers towards GM implementation. Unexpected results may cause a certain amount of loss of money. That's why companies don't want to take risks. However it should be reminded that to save money you have to spend money first to some extent. Taking into consideration of those barriers while approaching GM practices, companies can have an overview of difficulties to overcome.

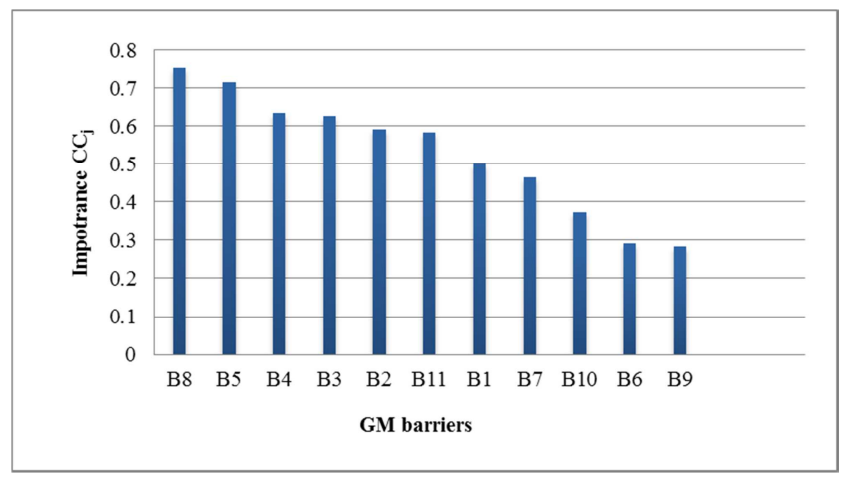

Figure 3. Importance of GM barriers.

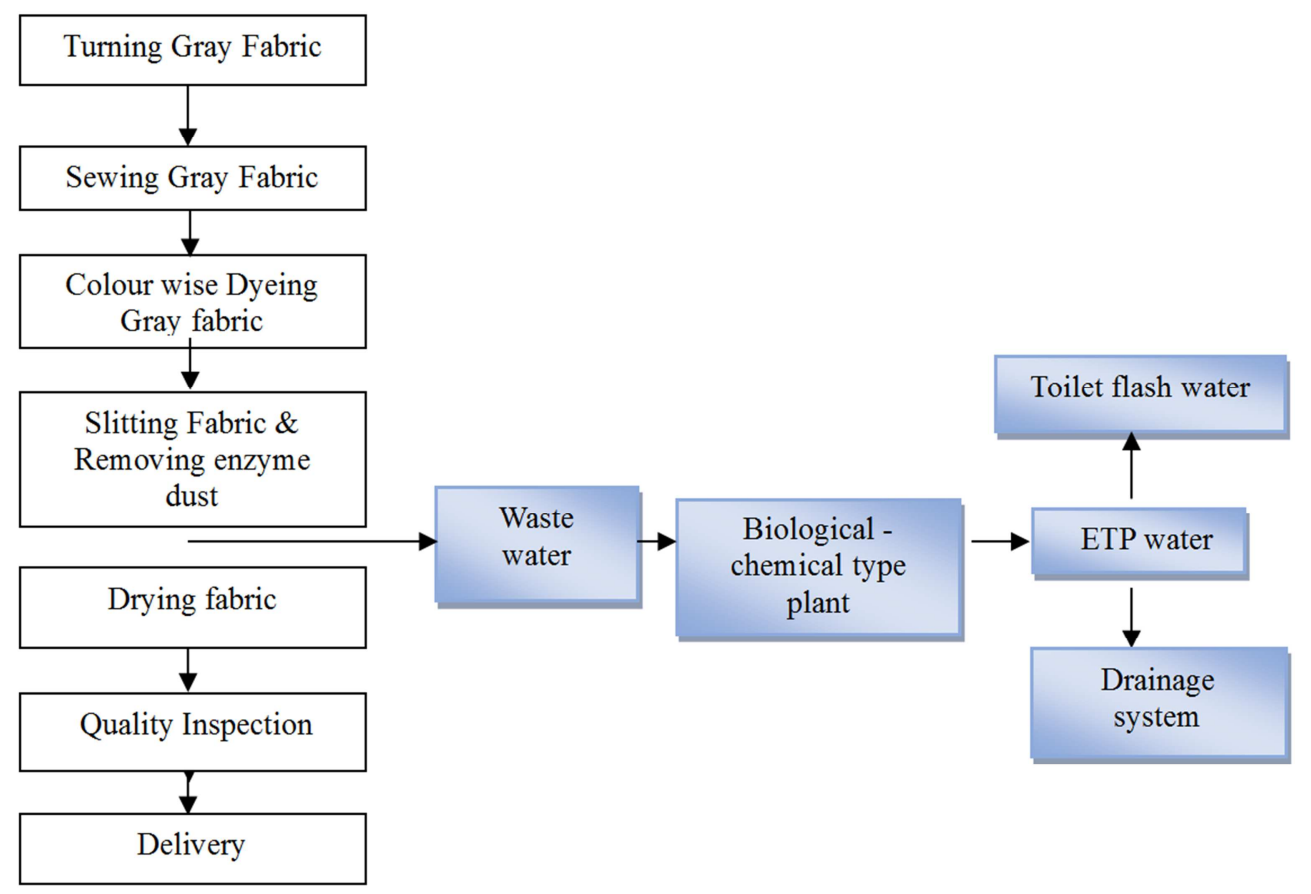

Figure 4. Modified process flow chart for dyeing process with ETP.

In figure 4 the black and white part is the existing dyeing process of a knitting industry of Bangladesh that discharge waste water after process without treating it. The colored part is the proposed waste water treatment process with ETP technology. Generally biological - chemical type effluent treatment plant is most widely used. Waste water is required primary, secondary or tertiary treatment based on its effluent level. After the treatment a certain amount of water can be used for toilet flash not having direct contact with human body. The rest of the water is sent to the drainage system.

\section{Conclusions and Recommendations}

To solve the real world decision making problem, Multi Criteria Decision Making (MCDM) is widely being used. It is embedded on the fact that, in some cases it is difficult to determine the weight of the criteria/ the weight of the alternatives with respect to criteria. In this paper fuzzy 
TOPSIS method was proposed to solve MCDM problem.

The investigation and prioritization of GM drivers and barriers suggest very interesting and useful results. In Bangladesh, The textile dyeing industries consume huge amounts of water and produces large volumes of wastewater from different steps in the dyeing and finishing processes. For proper treatment of waste water of dyeing section, an ETP is needed and is an initiative to have green manufacturing. After understanding the system model of green manufacturing for dyeing section, there is need for implementation, proper execution and looking for ways to improve the current level. Likewise dyeing section, knitting and yarn production are in a great need to be eco-friendly. Those would be useful area of research.

\section{References}

[1] Paul, L. D., Bholeb, G. P., and Chaudharic, J. R. (2014) 'A review on green manufacturing: it's important, methodology and its application', 3rd International Conference on Materials Processing and Characterisation (ICMPC 2014),6, $1644-1649$.

[2] Masupha, T. M. (2007) 'Water management at a textile industry: a case study in Lesotho', A Research Report, 1- 89.

[3] Talapatra, S., Uddin, M. K., \& Rahman, M. H. (2018). Development of an Implementation Framework for Integrated Management System Based on the Philosophy of Total Quality Management. American Journal of Industrial and Business Management, 8(6), 1507-1516.

[4] Berns, M., Bussey, K., Murray, S., and Vismans D. (2011) 'Sustainability: the 'embracers' seize advantage', Research Report by MIT Sloan Management Review and The BCG, 1 28.

[5] Mittal, V. K., and Sangwan, K. S. (2014) 'Development of a model of barriers to environmentally conscious manufacturing implementation', International Journal of Production Research, 52(2), 584-594.

[6] Mittal, V. K., and Sangwan, K. S. (2014) 'Modelling Drivers for Successful Adoption of Environmentally Conscious Manufacturing', Journal of Modelling in Management, 9(2), 127-140.

[7] Singh, A., Singh, B., and Dhingra, A. K. (2012) 'Drivers and barriers of green manufacturing practices: a survey of Indian industries', International Journal of Engineering Sciences1(1), 5-19.

[8] Singh, P. J, Mittal, V. K., and Sangwan, K. S. (2013) 'Development and validation of performance measures for environmentally conscious manufacturing', International Journal of Services and Operations Management, 14(2), 197220.

[9] Govindan, K., Diabat, A., and Shankar, K. M. (2015)
'Analyzing the drivers of green manufacturing with fuzzy approach, Journal of cleaner production, 96, 182-193.

[10] Duflou, J. R., Sutherland, J. W., Dornfeld, D., Herrmann, C., Jeswiet, J., Kara, S., Hauschild, M., and Kellens, K. (2012) 'Towards energy and resource efficient manufacturing: a processes and systems approach, CIRP Annals Manufacturing Technology, 61(2), 587-609.

[11] Ariffin, R., Ghazilla, R., Sakundarini, N., Hanim, S., Rashid, A., Ayub, N. S., Olugu, E. U., and Musa, S. N., (2015) 'Drivers and barriers analysis for green manufacturing practices in Malaysian SMEs: a preliminary findings', 12th Global Conference on Sustainable Manufacturing,26, 658 - 663.

[12] Post, J. E., and Altma, B. W. (1994) 'Managing the environmental change process: barriers and opportunities', Journal of Organizational Change Management, 7(4), 64 - 81.

[13] Luken, R., and Rompaey, F. V. (2008) 'Drivers for and barriers to environmentally sound technology adoption by manufacturing plants in nine developing countries', Journal of Cleaner Production, 16(1), 67-77.

[14] Wang, J. W., Cheng, C. H., and Huang, K. C. (2009) 'Fuzzy hierarchical TOPSIS for supplier selection', Applied Soft Computing, 9(1), 377-386.

[15] Jiang, Y. P., Fan, Z. P, and Ma, J. (2008)`A Method for group decision making with multigranularity linguistic assessment information', Information Sciences, 178(4), 1098-1109.

[16] Boran, F. E., Genc, S., Kurt, M., and Akay, D. (2009) 'A multi-criteria intuitionistic fuzzy group decision making for supplier selection with TOPSIS method', Expert Systemswith Applications, 36(8), 11363- 11368.

[17] Deif, A. M. (2011) 'A system model for green manufacturing', Advances in Production Engineering and Management,6(1), 27- 36.

[18] Kapdan, I. K., and Alparslan, S. (2005) 'Application of anaerobic-aerobic sequential treatment system to real textile wastewater for color and COD removal', Enzyme and Microbial Technology, 36(2-3), 273-279.

[19] Somasiri, W., Li, X. F., Ruan, W. Q., and Chen Jian, C. (2008) 'Evaluation of the efficacy of upflow anaerobic sludge blanket reactor in removal of color and reduction of COD in real textile wastewater', Bioresource Technology,99(9), 36923699 .

[20] Yang, Q., Li, C., Li, H., Li, Y., and Yu, N. (2009) 'Degradation of synthetic reactive azo dyes and treatment of textile wastewater by a fungi fonsortium reactor', Biochemical Engineering Journal, 43(3), 225-230.

[21] Talapatra, S., \& Rahman, M. H. (2016). Safety Awareness and Worker's Health Hazards in the Garments Sector of Bangladesh. European Journal of Advances in Engineering and Technology, 3(9), 44-49.

[22] Chen, C. T. (2000) 'Extensions of the TOPSIS for group decision-making under fuzzy environment', Fuzzy Sets and Systems, 114(1), 1-9. 